\title{
Safety and Efficacy of Long-Term Use of Extended Release Cornstarch Therapy for Glycogen Storage Disease Types 0, III, VI, and IX
}

Katalin M. Ross, Laurie M. Brown, Michelle M. Corrado, Tayoot Chengsupanimit, Latravia M. Curry, Iris A. Ferrecchia, Laura Y. Porras, Justin T. Mathew, Monika Dambska and David A. Weinstein*

Glycogen Storage Disease Program, Division of Pediatric Endocrinology, Department of Pediatrics, University of Florida College of Medicine, Gainesville, FL, USA

\begin{abstract}
Background: Impaired glycogen release with fasting results in hypoglycemia in the glycogen storage diseases. A waxy-maize extended release cornstarch was introduced in the United States in 2012 to maintain glucose concentrations during the overnight period, but no studies have assessed the long-term safety and efficacy of this product in the ketotic forms of GSD.

Objective: To assess long-term safety and efficacy of modified cornstarch in patients with ketotic forms of GSD.

Design: An open label overnight trial of extended release cornstarch was performed. Subjects who had a successful trial (defined as optimal metabolic control lasting 2 or more hours more than with traditional cornstarch) were given the option of continuing into the long-term observational phase. Participants were assessed biochemically at baseline and after 12 months.

Results: A total of 16 subjects participated in the open label trial. Efficacy was demonstrated in $100 \%$ of the subjects with GSD 0, III, VI, and IX. Of the patients who entered the longitudinal phase, long-term data are available for all subjects. The mean duration of overnight fasting on traditional cornstarch prior to the study for the cohort was 4.9 hours and 9.6 hours on the extended release cornstarch $(P<0.001)$. All laboratory markers of metabolic control have remained stable in the chronically treated patients.

Conclusion: Extended release cornstarch dramatically prolongs the overnight fast duration, maximizes safety from hypoglycemic events, reduces the possibility of sleep deprivation, and improves the quality of life of patients by eliminating the need to awaken without fail for middle of the night therapy without sacrificing metabolic control.
\end{abstract}

Keywords: Glycogen storage disease, uncooked cornstarch, extended release cornstarch, ketotic hypoglycemia.

\section{INTRODUCTION}

The ketotic forms of hepatic glycogen storage diseases are rare, inherited, metabolic disorders characterized by the abnormal storage (GSD 0 ) or release (GSD III, VI, and IX) of glycogen [1]. Hypoglycemia results from the inability of glycogen to breakdown while fasting. Since gluconeogenesis is intact, however, the extent of hypoglycemia is milder than is seen in type I GSD. Moreover, the patient can be asymptomatic due to the ketone body formation, which the brain can use as a source of energy, but chronic ketosis can result in long-term complications including poor growth, osteoporosis, and hepatic transaminase elevation $[2,3]$.

Maintaining normal blood glucose concentration is the main goal of treatment for all hepatic forms of GSD. In 1982, uncooked cornstarch therapy was introduced

*Address correspondence to this author at the P.O. Box 100296, Gainesville, FL 32610-0296, USA; Tel: (352) 273-5823; Fax: (352) 294-8113;

E-mail:weinsda@peds.ufl.edu as an alternative to continuous feeds to prevent hypoglycemia in GSD [4], and it has remained the standard therapy in North America. While some patients with the ketotic forms of GSD can tolerate an overnight fast with cornstarch therapy, many patients require therapy during the hours of sleep to prevent hypoglycemia and ketosis.

We previously described the efficacy of an extended release cornstarch therapy for maintaining glucose concentrations during the overnight period in GSD la and $\mathrm{lb}$ [5]. In 2009, the extended release waxy-maize cornstarch Glycosade ${ }^{\circledR}$ (Vitaflo International Ltd, Liverpool, United Kingdom) was approved in Europe for treatment of GSD, and it was released as a medical food in the United States in 2012. This waxy-maize product has been available to patients for several years, but the only publication on the long-term safety and efficacy of the therapy was limited to GSD I [6]. This paper describes our long-term, overnight experience with the extended release cornstarch in a cohort of patients with GSD types $0, \mathrm{III}, \mathrm{VI}$ and IX. 


\section{SUBJECTS AND METHODS}

\section{Subjects}

Patients followed by the University of Florida Glycogen Storage Disease Program with genetically proven GSD 0, III, VI and IX were eligible to participate. Inclusion was limited to patients 5 years of age and older who required overnight cornstarch therapy. A total of 16 eligible subjects ranging from 5 to 60 years of age chose to participate. This cohort consisted of 2 participants with GSD 0 ( 2 males), 8 with GSD III ( 3 males $/ 5$ females), 1 with GSD VI ( 1 male), and 5 with GSD IX (4 males/1 female). Long-term data have been collected from 16 of the patients as part of the longitudinal safety and efficacy trial. These studies were approved by the Institutional Review Board of the University of Florida. Prior to enrollment in this study, informed consent was required from a parent of every participant less than 18 years old and assent was obtained from the participant, if 7 to 18 years of age. All procedures followed were in accordance with the ethical standards of the responsible committee on human experimentation (institutional and national) and with the Helsinki Declaration of 1975 , as revised in 2000 [5]. Informed consent was obtained from all patients for being included in the study.

\section{Study Design}

Since there are no established dosing standards for the extended release cornstarch, the dose of the product for the overnight challenge was calculated by replacing the carbohydrate load provided by traditional cornstarch with a comparable amount of the new formulation over the same period of time. For the overnight challenge, an indwelling intravenous catheter was placed, and hourly monitoring of glucose and lactate was performed using a YSI 2300 STAT Plus ${ }^{\mathrm{TM}}$ Glucose \& Lactate Analyzer (YSI Incorporated, Yellow Springs, Ohio) until glucose concentrations fell to 70 $\mathrm{mg} / \mathrm{dL}$ or patients fasted for 12 hours. Ketone monitoring was performed hourly with a Precision Xtra portable ketone meter (Abbot Laboratories, Indianapolis, IN). Lactate concentrations over $5 \mathrm{mmol} / \mathrm{L}$ or beta-OH-butyrate concentrations over $0.5 \mathrm{mmol} / \mathrm{L}$ were established as stop criteria, but they were never reached.

Following completion of the overnight trial, patients were given the option of staying on the product chronically during the overnight period. All participants remained on their baseline cornstarch and protein therapies throughout the day. Doses of both the daytime and overnight cornstarch preparations were titrated over the course of the year based upon home glucose and ketone monitoring as per standard GSD care to maintain glucose concentrations over $75 \mathrm{mg} / \mathrm{dL}$ $(4.2 \mathrm{mmol} / \mathrm{L})$ and ketones under $0.3 \mathrm{mmol} / \mathrm{L}$. For inclusion in the follow-up safety and efficacy studies, the extended release cornstarch needed to be consumed at least 3 nights per week. Aspartate aminotransferase (AST), alanine aminotransferase (ALT), cholesterol, triglycerides, uric acid, total protein, creatine kinase $(\mathrm{CK})$, albumin, and prealbumin values were collected at 12 months and compared to the subjects' baseline values.

\section{Statistical Analysis}

For the overnight trial, success was defined as maintaining glucose concentrations above $70 \mathrm{mg} / \mathrm{dL}$ at least 2 hours longer than with traditional uncooked cornstarch with comparable markers of metabolic control. Statistical analysis was performed using paired two-tailed t-tests to determine whether there were differences between the metabolic markers before treatment and after 12 months. $P$-values $<0.05$ were considered statistically significant.

\section{RESULTS}

\section{Overnight Challenge}

A total of 16 subjects (10 males/ 6 females) participated in the overnight challenge. Efficacy of extending fasting for 2 hours beyond baseline with the waxy-maize cornstarch in GSD 0, III, VI, and IX was demonstrated in $100 \%$ of participants.

\section{Long-term Safety and Efficacy Follow-up}

A total of 16 patients chose to participate and have long-term safety and efficacy data as part of the longitudinal study (Figure 1).

The mean duration of overnight fasting on traditional cornstarch prior to the study for the cohort was 4.9 hours. Overnight fasting reached a mean of 9.6 hours on the extended release cornstarch $(P<0.001$ for all types). For type III, the average increase of fasting duration on extended release waxy-maize cornstarch was 4.69 hours, while for types $0, \mathrm{VI}$, and IX, the average increase was 4.75 hours (Figures 2-3).

All laboratory markers of metabolic control have remained stable in the chronically treated patients (Tables 1-2). 


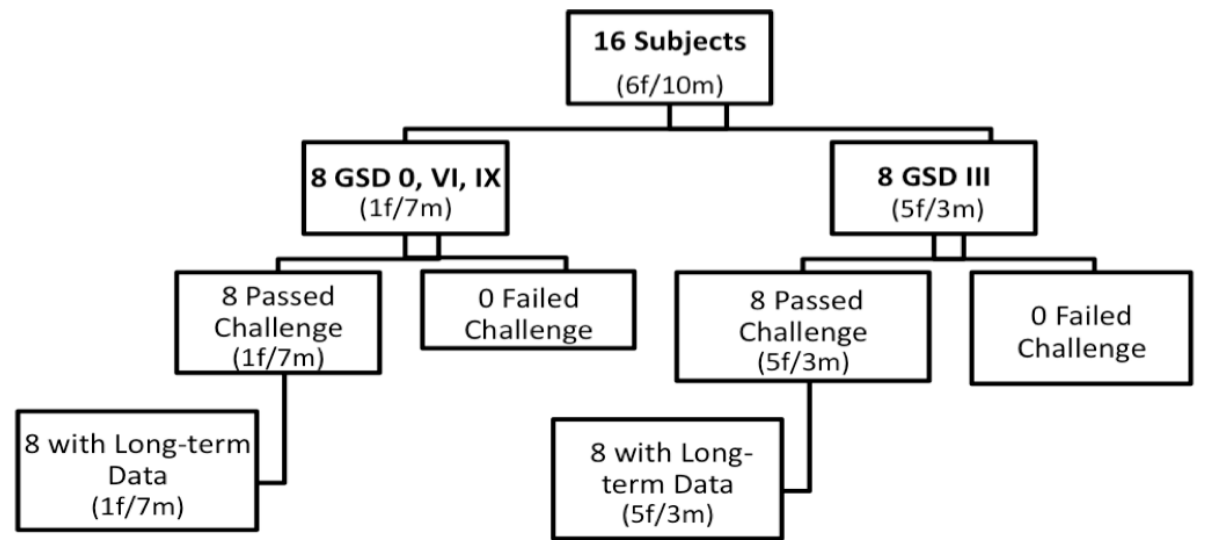

Figure 1: Participants status post-challenge.

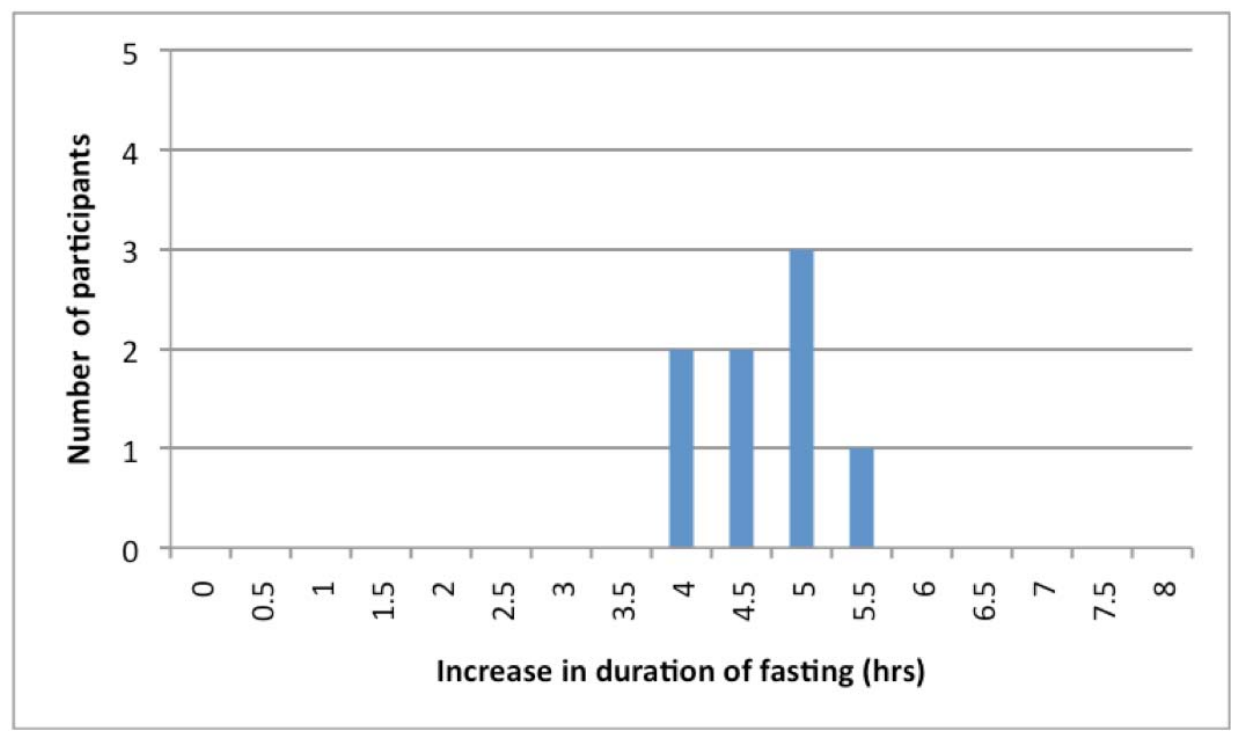

Figure 2: Duration of fasting increase on extended release waxy-maize cornstarch compared to uncooked cornstarch (UCCS) for Type III.

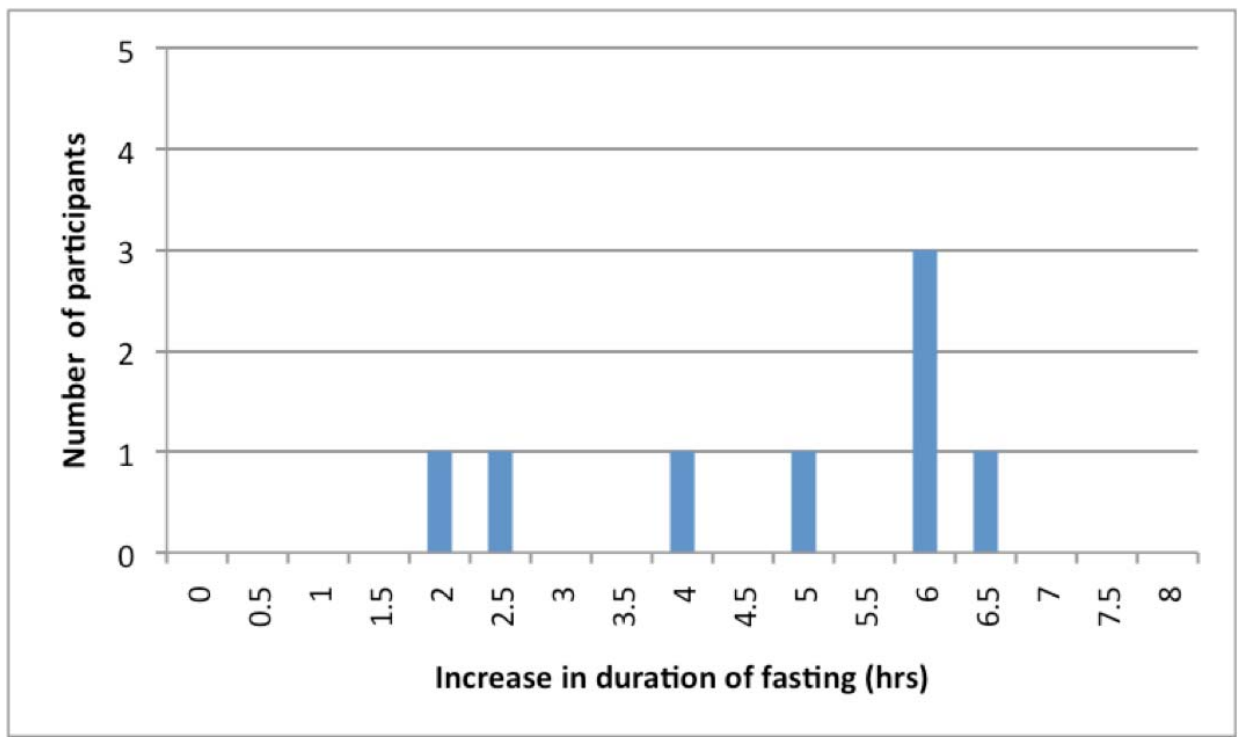

Figure 3: Duration of fasting increase on extended release waxy-maize cornstarch compared to uncooked cornstarch (UCCS) for Types 0, VI, IX. 
Table 1: Glycogen Storage Disease Type III Metabolic Markers before and after Extended Release Cornstarch Therapy

\begin{tabular}{|c|c|c|c|c|c|}
\hline & $\begin{array}{l}\text { Pre-therapy } \\
\text { mean } \pm \text { SD } \\
(n=8)\end{array}$ & $\begin{array}{l}\text { Pre-therapy } \\
\text { range }\end{array}$ & $\begin{array}{l}\text { Post-therapy (12 mo) } \\
\text { mean } \pm \text { SD } \\
(n=8)\end{array}$ & $\begin{array}{l}\text { Post-therapy } \\
\text { range }\end{array}$ & $P$-value \\
\hline $\operatorname{ALT}(\mathrm{U} / \mathrm{L})$ & $154.0 \pm 128.6$ & $15-432$ & $136.3 \pm 91.1$ & $17-299$ & 0.46 \\
\hline Cholesterol (mg/dL) & $157.4 \pm 41.9$ & $11-223$ & $164.9 \pm 43.2$ & $120-239$ & 0.38 \\
\hline Uric Acid (mg/dL) & $3.5 \pm 1.0$ & $2-5.1$ & $3.4 \pm 1.0$ & $2-4.5$ & 0.94 \\
\hline Protein $(\mathrm{g} / \mathrm{dL})$ & $6.9 \pm 0.3$ & 6.3-7.2 & $7.0 \pm 0.4$ & $6.5-7.6$ & 0.20 \\
\hline Albumin (g/dL) & $4.1 \pm 0.3$ & $3.5-4.5$ & $4.1 \pm 0.5$ & $3.2-4.7$ & 1.00 \\
\hline CK (IU/L) & $1544.9 \pm 1192.0$ & $138-2941$ & $1143.6 \pm 660.5$ & $124-1896$ & 0.32 \\
\hline
\end{tabular}

Table 2: Glycogen Storage Disease Ketotic Forms (0, VI, IX) Metabolic Markers before and after Extended Release Cornstarch Therapy

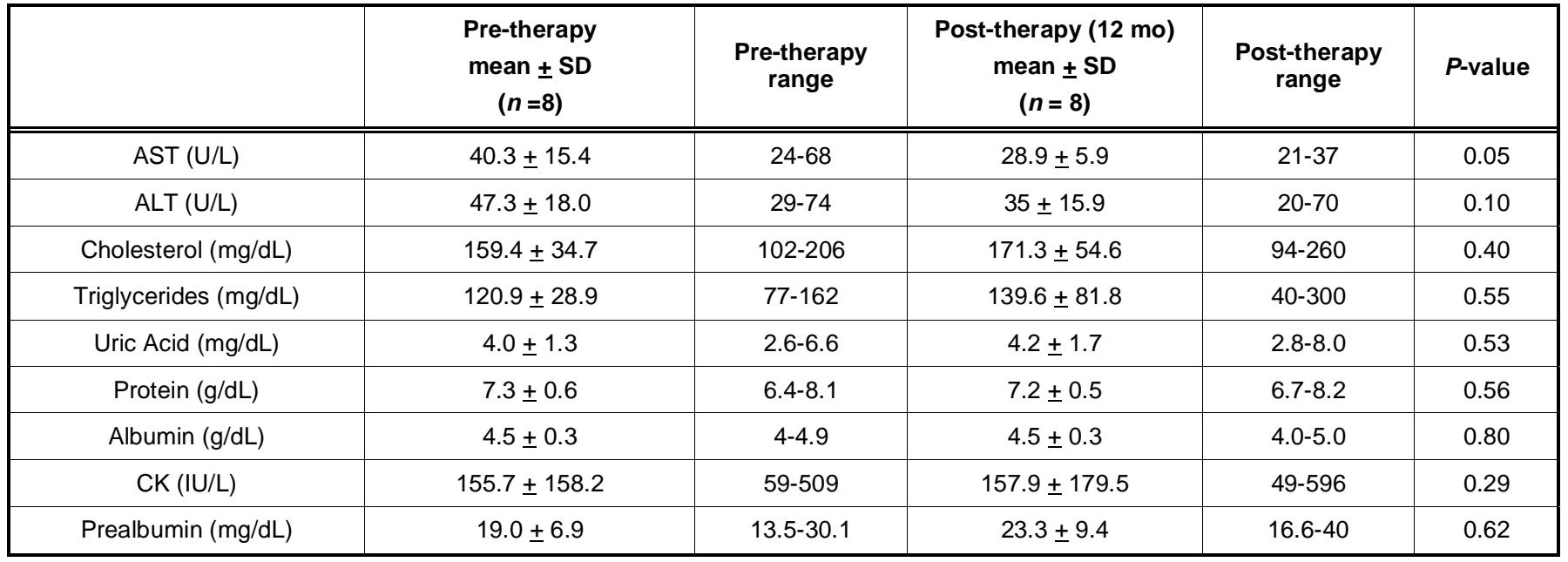

\section{DISCUSSION}

Continuous glucose therapy was the first medical treatment described for glycogenoses [7]. Cornstarch therapy replaced continuous feeds in the 1980s, improving metabolic control and thus long-term prognosis for all of the hepatic forms of GSD [4]. Extended release waxy-maize cornstarch was introduced in 2009 as the first new treatment for the hepatic GSDs since uncooked cornstarch therapy had been described. The product was approved as a medical food based mostly on short-term studies in GSD types la and Ib $[5,8]$, and no studies on the longterm efficacy and safety of this therapy in the ketotic forms of GSD have been published.

While GSD types $0, \mathrm{III}, \mathrm{VI}$, and IX are milder than GSD I, some patients still require overnight therapy.
Overnight treatment is often required in childhood in GSD III, and there is a subset of patients with GSD IX with mutations in PHKG2 and PHKA2 that have a severe phenotype similar to that seen in GSD I [9]. Inadequate therapy in all of the ketotic forms of GSD results in overnight hypoglycemia and ketosis, and this has been associated with short stature, osteopenia, and even neurologic complications. Cirrhosis can occur in GSD III and IX, and there is increasing evidence that many of the complications in GSD 0, III, VI, and IX can be prevented by optimal metabolic control [9]. In this study, biochemical markers of metabolic remained stable in the chronically treated cohort while quality of life and safety were maximized by avoidance of the overnight therapy. It is too early, however, to determine if avoidance of the overnight therapy will result in fewer long-term complications. 
It is important to emphasize that not all patients with GSD 0, III, VI, and IX require a middle of the night feed. Patients with these types of GSD should have morning glucose and ketone determinations, and the new therapy should be limited to only those with morning hypoglycemia or ketosis. Cost of this extended release cornstarch is 15 times higher than regular cornstarch (approximately $\$ 4.00$ per night vs $\$ 0.28$ per night), and the extra expense can be justified for those needing overnight support where a missed dose of cornstarch puts the child at risk for severe hypoglycemia.

While the new cornstarch therapy may help improve safety and quality of life for people and families living with GSD, it must be emphasized that protein supplementation is also important in these conditions. Protein serves as a precursor for gluconeogenesis, and protein helps to prevent muscle damage in GSD III [10]. If fewer feeds are administered as a result of treatment with waxy-maize extended release cornstarch, monitoring of prealbumin concentrations should occur to ensure that adequate protein supplementation is occurring.

Daytime use of extended release cornstarch has also not been formally studied in any of the glycogen storage diseases. While there have been case reports at conferences discussing successful use of the product during the day, no daytime studies have been published, and formal investigation of daytime use is warranted before use can be recommended. Higher energy demands during the day may not be adequately being covered with the slower release therapy.

In conclusion, patients with ketotic types of GSD were able to benefit from the extended release cornstarch by avoiding the overnight dose without diminishing metabolic control. For the first time, the therapy was demonstrated to be an effective long-term treatment for the ketotic forms of GSD. This is a reassuring study, but patients should be followed closely to monitor the need for dose changes, and metabolic control.

\section{ACKNOWLEDGEMENTS}

$\mathrm{KR}, \mathrm{MC}$, and DW designed the research study, and $\mathrm{KR}$, LB and DW conducted the research. JM performed statistical analysis, and all authors contributed to the data collection, data analysis, and writing of the manuscript. KR, LB, TC, and DW had primary responsibility for the final content, and all authors read and approved the final manuscript. The authors would like to thank Connie L. Cauthen for her help organizing inpatient visits for the participant of the study and University of Florida Health Clinical Research Center in-patient nurses (Charles J. Church, Emma B. Labrador, Dorothy G. Nichols, and Elizabeth A. Potocik) for the great care that they provide.

\section{FUNDING}

This research was supported by philanthropic support provided by the Furtherance Fund and the following funds managed through the University of Florida Office of Development: Scott Miller GSD Program Fund, GSD Dream Fund, Green Family Fund for GSD Research, Ralph and Alice Brown Type VI GSD Research Fund, and the Matthew's GSD Type IX Fund. This work was also supported in part by the NIH/NCATS Clinical and Translational Science Award UL1 TR000064 granted to the University of Florida.

\section{DISCLAIMER}

The authors have no conflict of interest or financial interest in any of the research presented in this manuscript.

\section{CONFLICT OF INTEREST}

Katalin M. Ross, Laurie M. Brown, Michelle M. Corrado, Tayoot Chengsupanimit, Latravia M. Curry, Iris A. Ferrecchia, Laura Y. Porras, Justin T. Mathew, Monika Dambska and David A. Weinstein declare they have no conflict of interest.

\section{INFORMED CONSENT}

All procedures followed were in accordance with the ethical standards of the responsible committee on human experimentation (institutional and national) and with the Helsinki Declaration of 1975 , as revised in 2000 [5]. Informed consent was obtained from all patients for being included in the study.

\section{ABBREVIATIONS}

$$
\begin{aligned}
& \text { GSD }=\text { glycogen storage disease } \\
& \text { AST }=\text { aspartate aminotransferase } \\
& \text { ALT }=\text { alanine aminotransferase } \\
& \text { CK }=\text { creatine kinase } \\
& \text { UCCS }=\text { uncooked cornstarch }
\end{aligned}
$$

\section{REFERENCES}

[1] Wolfsdorf JI, Weinstein DA. Glycogen storage diseases. Rev Endocr Metab Disord 2003; 4: 95-102. http://dx.doi.org/10.1023/A:1021831621210 
[2] Kishnani PS, Austin SL, Arn P, Bali DS, Boney A, Case LE, Chung WK, Desai DM, El-Gharbawy A, Haller $\mathrm{R}$, et al. Glycogen storage disease type III diagnosis and management guidelines. Genet Med 2010; 12: 446-63. http://dx.doi.org/10.1097/GIM.0b013e3181e655b6

[3] Brown LM, Corrado MM, van der Ende RM, Derks TG, Chen MA, Siegel S, Hoyt K, Correia CE, Lumpkin C, Flanagan TB, et al. Evaluation of glycogen storage disease as a cause of ketotic hypoglycemia in children. J Inherit Metab Dis 2015; 38(3): 489-93.

http://dx.doi.org/10.1007/s10545-014-9744-1

[4] Chen YT, Cornblath M, Sidbury JB, Cornstarch therapy in type I glycogen-storage disease. N Engl J Med 1984; 310: 171-5. http://dx.doi.org/10.1056/NEJM198401193100306

[5] Correia CE, Bhattacharya K, Lee PJ, Shuster JJ, Theriaque DW, Shankar MN, Smit GP, Weinstein DA. Use of modified cornstarch therapy to extend fasting in glycogen storage disease types la and Ib. Am J Clin Nutr 2008; 88: 1272-6.

[6] Ross KM, Brown LM, Corrado MM, Chengsupanimit T, Curry LM, Ferrecchia IA, Porras LY, Mathew JT, Weinstein DA.
Safety and efficacy of chronic extended release cornstarch therapy for glycogen storage disease type I. J Inherit Metab Dis [Epub ahead of print].

[7] Crigler JF Jr, Folkman J. Glycogen storage disease: new approaches to therapy. Ciba Found Symp 1977; 55: 331-51.

[8] Bhattacharya K, Orton RC, Qi X, Mundy H, Morley DW, Champion MP, Eaton S, Tester RF, Lee PJ. A novel starch for the treatment of glycogen storage disease. J Inherit Metab Dis 2007; 30: 350-7. http://dx.doi.org/10.1007/s10545-007-0479-0

[9] Tsilianidis LA, Fiske LM, Siegel S, Lumpkin C, Hoyt K, Wasserstein M, Weinstein DA. Aggressive therapy improves cirrhosis in glycogen storage disease type IX. Mol Genet Metab 2013; 109: 179-82. http://dx.doi.org/10.1016/j.ymgme.2013.03.009

[10] Derks TG, Smit GPA. Dietary management in glycogen storage disease type III: what is the evidence? J Inherit Metab Dis 2015; 38(3): 545-50 http://dx.doi.org/10.1007/s10545-014-9756-x

\section{DOI: http://dx.doi.org/10.6000/1929-5634.2015.04.04.5}

(C) 2015 Ross et al.; Licensee Lifescience Global.

This is an open access article licensed under the terms of the Creative Commons Attribution Non-Commercial License (http://creativecommons.org/licenses/by-nc/3.0/) which permits unrestricted, non-commercial use, distribution and reproduction in any medium, provided the work is properly cited. 